\title{
】 DA "IMOBILIDADE" À AÇÃO: POR QUE OS BRASILEIROS SAÍRAM ÀS RUAS EM JUNHO DE 2013? O CONTÁGIO COMPORTAMENTAL COMO PARTE DA EXPLICAÇÃO
}

\section{FROM "IMMOBILITY" TO ACTION: WHY HAVE BRAZILIANS TAKEN THE STREETS IN JUNE 2013? BEHAVIORAL CONTAGION AS PART OF THE EXPLANATION}

Thiago Lopes Carneiro*

Resumo: As manifestações ocorridas em junho de 2013 no Brasil desafiam os cientistas sociais. Este artigo discute o emprego do conceito de Contágio Comportamental para explicar a imensa mobilização. Revisam-se a teoria e os achados empíricos em torno do conceito. Conclui-se que o Contágio Comportamental pode explicar uma parte importante da ação coletiva, o que pode ser mais bem explorado em estudos empíricos futuros.

Palavras-chaves: Contágio comportamental; Ação coletiva; Participação política; Manifestações de junho de 2013; Revisão teórica.

Abstract: The demonstrations occurred in June 2013 in Brazil challenge social scientists. This article discusses the concept of Behavioral Contagion as a tool to explain such a huge mobilization. Theory and empirical findings on the concept are reviewed. Behavioral Contagion may explain an important part of collective action which can be further explored in future empirical studies.

Keywords: Behavioral contagion; Collective action; Political participation; June 2013 street demonstrations; Theoretical review.

La politique est une religion remise sur ses pieds ${ }^{1}$

Serge Moscovici, 1985

\footnotetext{
* Doutorando em Psicologia Social na Universidade de Brasília, mestre em Psicologia Social (Ergonomia) e graduado em Psicologia. Atualmente é analista legislativo da Câmara dos Deputados, membro do Laboratório Hacker (thiago.carneiro@ camara.leg.br).

${ }^{1}$ Na tradução literal, Moscovici afirma que "a política é uma religião de volta a seus pés"; a expressão não pode ser diretamente traduzida para o português. Moscovici quer dizer, em uma tradução semanticamente sensível, que "a política é uma nova forma de religião", ou, em outras palavras, que "a política foi edificada no mesmo lugar antes ocupado pela religião, usando os mesmos alicerces (seus 'pés')".
} 


\section{Introdução}

As manifestações ocorridas no Brasil em junho de 2013 surpreenderam políticos, jornalistas, cientistas sociais (sociólogos, cientistas políticos, psicólogos sociais) e até mesmo os próprios participantes das manifestações (MOREIRA e SANTIAGO, 2013; NOGUEIRA, 2013). Uma mobilização popular digna de momentos marcantes da história do país (como Diretas Já e o Impeachment de Collor) desafia quem tenta explicar o que aconteceu (ANTUNES, 2013). Afinal, o que levou tanta gente às ruas para protestar? Se estas insatisfações existiam há mais tempo, por que somente nesse momento vieram os protestos?

A realidade social é multideterminada; por isso, qualquer explicação que se construa será necessariamente incompleta (KONDER, 1984). Cabe ao cientista social contribuir com uma parcela da explicação do fenômeno. Vários processos psicológicos podem ser investigados nessa tentativa de entender os episódios de manifestações populares. Mas uma questão que sempre intriga os psicólogos sociais é: o que leva as pessoas a transformarem motivações ou atitudes (suas “intenções") em ações reais? Ou uma questão ainda mais intrigante: o que explica tantas pessoas partindo para a ação simultaneamente? Este artigo pretende debater a possível influência do contágio comportamental na transmissão das ideias e na mobilização dos cidadãos que deixaram o conforto de suas casas para pedir um país melhor.

\section{0 estudo da ação coletiva}

Para Cho e Rudolph (2008), há uma aparente tradição das ciências sociais de investigar comportamentos individuais e, a partir deles, traçar inferências sobre os comportamentos da coletividade, o que se reflete em diversos problemas quanto ao nível de análise (indivíduo ou grupo) na interpretação dos resultados desses estudos. Inquietado diante dessa crítica, este artigo visa discutir o emprego do conceito de "contágio comportamental" no estudo da ação coletiva, entendendo-a como algo mais complexo do que a soma das ações individuais, de modo que seja útil para a psicologia e para outras ciências que se atrevem a investigar os movimentos de massa.

A obra clássica de Gustave Le Bon (2008 [1895]), "Psicologia das Multidões", é considerada um marco importante para o entendimento da ação coletiva. A obra é, ao mesmo tempo, elogiada pela descrição verossímil dos processos de ação e decisão coletiva e criticada pelo viés pessimista e até mesmo antidemocrático do pensamento do autor (CONSOLIM, 2008; MCGUIRE, 1987; MOSCOVICI, 1985). A opção de iniciar por esta controvertida obra se justifica pela sua influência sobre teorias posteriores; além disso, o estudo do comportamento de multidões não se encontra consolidado sob a forma uma teoria dominante, embora as teorias referenciadas adiante possuam vários pontos em comum. 


\section{As ideias de Le Bon}

Le Bon (2008) inicia "Psicologia das Multidões" afirmando categoricamente que as grandes mudanças da civilização têm, por trás das causas aparentes, uma profunda mudança nas ideias dos povos - suas opiniões, concepções e crenças. O autor sinaliza que, à época em que escrevia o livro (publicado pela primeira vez em 1895), as multidões tomavam consciência de sua imensa força, como resultado da "propagação de certas ideias lentamente implantadas nos espíritos" (p.21). Antes dessa tomada de consciência, afirma, as civilizações foram criadas e mantidas por uma pequena aristocracia intelectual, mas "nunca pelas multidões" (p.23).

Adotando um tom deveras pessimista, Le Bon afirma que as multidões são impulsivas, muito pouco aptas ao raciocínio, mas muito aptas para a ação; além disso, as multidões têm poder apenas para destruir, nunca para construir. O autor sugere que líderes fortes (Le Bon usa a expressão "senhores do mundo", p. 24) possuem um conhecimento instintivo da alma das multidões, sendo capazes de dominá-las e conduzi-las a um objetivo declarado. Em contraponto à "irracionalidade" e à "mediocridade" das multidões, Le Bon exalta as elites, sugerindo-lhes que conheçam a alma de seu povo para evitar seu potencial destrutivo e preservar a estabilidade social (NYE, 1973). Essas afirmativas deram espaço para uma tempestade de críticas ao autor (CONSOLIM, 2008).

Essas ideias de Le Bon, na verdade, não destoavam das de outros pensadores do final do século XIX e início do Século XX, como Hippolyte Taine, Herbert Spencer, Friedrich Nietzsche e Gabriel Tarde. Em comum, estes autores receberam influências do darwinismo social, que apregoava que certos seres humanos teriam se beneficiado de melhor evolução genética ou ganhos na esfera social, e deveriam constituir as elites condutoras da sociedade (CONSOLIM, 2008; MIGUEL, 2002; RIBEIRO, 2001). Esses autores estavam particularmente preocupados ante as "rebeliões das massas" que instalariam um igualitarismo "imoral", aniquilando o respeito à hierarquia "natural". Max Weber, de forma mais complexa, apresenta o surgimento inevitável do político profissional como algo necessário à eficiência da burocracia. Para Joseph Schumpeter (que se reporta a Le Bon), as massas não sabem definir o que é o bem comum nem escolher racionalmente seus representantes; portanto, cabe às elites competirem entre si pelo voto dos cidadãos, num jogo que determinará qual líder prevalecerá (MIGUEL, 2002).

A leitura de "Psicologia das Multidões" requer do leitor um acentuado relativismo, para considerar que o tom aristocrático do livro tem raízes no zeitgeist - o ambiente intelectual da época em que foi escrito (MCGUIRE, 1987). Primeiramente, contrariando o senso comum, a democracia nem sempre foi bem vista. Bresser-Pereira (2011) explica que, até o final do século XIX, filósofos políticos como Benjamin Constant e Jean-Jacques Rousseau defendiam o Estado liberal como forma de limitar constitucionalmente os poderes do monarca, mas tinham aversão à ideia de democracia representativa, pois ela poderia levar à instabilidade e à desordem. A insistência de Le Bon sobre a irracionalidade das multidões encontra raízes em Les origines de 
la France contemporaine, de Hippolyte Taine (1885) e na popularidade dos estudos sobre hipnose (MCGUIRE, 1987; NYE, 1973). A influência do evolucionismo de Herbert Spencer levou o autor a refutar a igualdade entre os indivíduos, assumindo-se que suas diferenças intelectuais se davam por suas características hereditárias (JESUS, 2013; MCGUIRE, 1987; ZIMMERMANN, 1992).

Apesar da polêmica, as questões levantadas por Le Bon moveram a elaboração de vários outros trabalhos ao longo do século XX. Formaram-se pesquisadores que deram continuidade às ideias aristocráticas de Le Bon, mas também pesquisadores que se opuseram a isso e buscaram dar uma roupagem mais "imparcial" à sua análise (JESUS, 2013; MCGUIRE, 1987; NYE, 1973; SANDOVAL, 1997; ZIMMERMANN, 1992). Não se encontraram estudos que façam uma contundente refutação dos fenômenos descritos por Le Bon. Pelo contrário: à parte as controvérsias, os achados científicos posteriores dão respaldo e lapidam os conceitos do autor. Mas, afinal, o que este autor diz que pode ser útil para compreender os comportamentos das coletividades? Vamos, então, aos principais conceitos de "Psicologia das Multidões".

Le Bon formula a "lei de unidade mental das multidões", apontando que em condições específicas a personalidade consciente dos indivíduos desaparece; seus sentimentos e ideias orientam-se em uma mesma direção. Forma-se, assim, uma multidão psicológica:

O desaparecimento da personalidade consciente e a orientação dos sentimentos e dos pensamentos em um mesmo sentido, primeiros traços da multidão em via de organização, nem sempre implicam a presença simultânea de vários indivíduos em um mesmo local. Milhares de indivíduos separados podem em um dado momento, sob a influência de certas emoções violentas, um grande acontecimento nacional, por exemplo, adquirir características de uma multidão psicológica. Um acaso qualquer que os reúna bastará para que sua conduta logo se [...] [converta na] forma específica dos atos das multidões (LE BON, 2008, p. 30, grifo nosso).

O termo "alma das multidões" é utilizado por Le Bon para enfatizar que as multidões se comportam de forma muito diferente da soma dos comportamentos dos indivíduos. Além disso, as multidões não se resumem a um aglomerado aleatório de pessoas; a sua "alma" é o que permite que ela seja identificada como uma multidão. A explicação para que pessoas intelectualmente diferentes se juntem em torno de uma alma coletiva é, para Le Bon, a semelhança de seus instintos, paixões, sentimentos, o que inclui sua moral, afetos, antipatias e crenças políticas e religiosas.

Não apenas os fatores contextuais podem explicar a formação da alma das multidões. Le Bon enumera três possíveis causas da formação de uma multidão psicológica, ligadas a características humanas:

a) a sugestionabilidade é considerada pelo autor a causa mais importante. Segundo ele, o indivíduo em multidão fica em estado próximo ao de hipnose, sendo facilmente conduzido pela sugestão. $\mathrm{O}$ indivíduo perde a consciência de seus atos e passa a se guiar pela corrente formada pelos demais; 
b) o sentimento de poder invencível, que deriva do fato de participar de um grupo numericamente grande. A multidão torna-se anônima e irresponsável, e os indivíduos cedem a instintos que em outras circunstâncias seriam imediatamente refreados;

c) o contágio mental advém do efeito hipnótico de participação em uma multidão. Nela, "todo ato é contagioso, e contagioso ao ponto de que o indivíduo sacrifique muito facilmente o seu interesse pessoal ao interesse coletivo" (LE BON, 2008, p. 35).

Os argumentos de Le Bon em torno da sugestionabilidade são deveras controversos, por sua ligação com a hipnose (CONSOLIM, 2008; JESUS, 2013; MCGUIRE, 1987; NYE, 1973). Pesquisas recentes não trabalham com a noção de hipnose, mas indicam que, quando em grupo, as pessoas tendem a repetir o comportamento de alguém que serve como modelo, com reduzida autocrítica (AARTS, GOLLWITZER, HASSIN; 2004; e BONO e ILIES, 2006; CACIOPPO e HAWKLEY, 2009; DIK e AARTS; 2007; FREEDMAN e PERLICK, 1979; KRASSA, 1988). O sentimento de poder invencível é corroborado por Reicher (2001).

Le Bon destaca ainda que as ideias fundamentais de um povo estão em lenta e constante mutação; neste sentido, as revoluções expressam o abandono de velhas crenças em favor de novas, demarcando momentos de importante mudança e consolidação de uma nova visão de mundo.

Mantendo distância do viés pessimista e aristocrático do autor, e numa tentativa de compreender o contágio de forma não pejorativa, cabe questionar se existe um efeito multiplicador que pode aumentar as chances de um indivíduo participar de uma ação coletiva ainda que por força da imitação de amigos ou outras pessoas próximas. É possível que sentimentos compartilhados diante de um grande acontecimento nacional mobilizem multidões a um protesto ou a outra forma de ação política. O exemplo do comportamento de alguém próximo pode levar um indivíduo a transformar sua intenção em ação. Para o presente artigo, em lugar do leboniano "contágio mental", passa-se a utilizar a expressão "contágio comportamental", o que coloca ênfase sobre a imitação de ações e reduz a ambiguidade terminológica (NICOL, 1995), evitando o infrutífero debate em torno de uma concepção dualista (mente-corpo) ou monista (somente corpo) de ser humano (RYLE, 1951).

\section{0 que motiva as pessoas a imitar?}

A principal crítica à tese da motivação irracional das multidões é motivada pela clara intenção de Le Bon de condenar os movimentos populares, as instituições democráticas e as aspirações coletivas (MARGOT-DUCLOS, apud MCGUIRE, 1987). ZIMMERMANN (1992) aponta que a insustentável defesa de Le Bon quanto à superioridade anglo-saxã em relação à "raça latina", meramente por fatores hereditários, forneceu argumentos para uma série de pesquisadores e políticos de viés antidemocrático. Jesus (2013) afirma que "essa superada visão racialista das massas pode ser uma das explicações para o mal-estar que a discussão sobre 
multidões causa ainda hoje e para a falta de pesquisas aplicadas à realidade brasileira" (p. 500).

Sandoval (1997), em tom de crítica, aponta que a sociologia partiu do pressuposto de que o indivíduo seria passivamente conduzido pelas ideologias da classe dominante, por meio do aprendizado das normas e valores sociais, e que a psicologia social, como legado de Le Bon, colocou o coletivo sob suspeita. Na interpretação da psicologia, os indivíduos teriam sua criatividade inibida, sendo levados ao conformismo em troca de serem aceitos pelo grupo. Sandoval destaca que tanto a sociologia quanto a psicologia assumiram o pressuposto da irracionalidade do indivíduo no contato com o meio social.

Cialdini e Trost (1998) levantam uma interessante questão: afinal, que razões teriam os indivíduos para aceitar a influência de outrem? Sob um olhar ingênuo, parece não haver ganho em ser "vítima" de uma ação de influência; mas os autores argumentam que há ganho, sim. O influenciado tem, em uma primeira instância, a redução da incerteza sobre que comportamento tomar em uma determinada situação, ganhando com isso sua aceitação como membro de um grupo. A elevação da autoestima do influenciado também funciona como uma forma de recompensa pela aquiescência aos objetivos do influenciador ou do grupo (o que é corroborado por SIMON et al., 1998; e por VAN STEKELENBURG e KLANDERMANS, 2013). McGuire (1987), por sua vez, sugere a possibilidade de se desenvolver uma versão pró-social de psicologia das multidões, ou seja, é possível admitir situações de comportamento de massa em que os participantes estejam conscientes de suas ações e tomam a decisão deliberada de participar ou não da multidão.

\section{Avanços Teóricos Recentes}

$\mathrm{O}$ viés aristocrático de Le Bon é, na maioria das vezes, rechaçado pelos pesquisadores que o sucederam (JESUS, 2013; MCGUIRE, 1987). Teóricos de expressivo reconhecimento no século XX buscaram novas formas de explicar o contágio e a sugestionabilidade das multidões. Freud (1921), em Psicologia das Massas e a Análise do Eu, substituiu o "estado hipnótico" da multidão leboniana por impulsos da libido movidos pela identificação com a coletividade. Wilfred Trotter (1921), em Instincts of the herd in peace and war ("Instintos de rebanho na paz e na guerra", sem tradução para o Brasil) substitui a sugestionabilidade das multidões pelo instinto gregário de rebanho, afirmando que a racionalidade individual pode ser vista como um impedimento para a integração do rebanho. William McDougall (1927), em The group mind (A mente do grupo, sem tradução para o Brasil) aponta para a telepatia (que ficou carente de verificação empírica) e a consciência coletiva dos grandes grupos, enfatizando que o indivíduo abdica de sua cognição e do controle de suas ações quando está em grupo. Neil Smelser (1965), em Theory of collective behavior (Teoria do comportamento coletivo, sem tradução para o Brasil), esforça-se para manter distância de Le Bon, mas corrobora que o comportamento coletivo é movido por "crenças gerais" de caráter histérico e, portanto, sugestionável. Serge 
Moscovici (1985), em L'age des foules (A era das multidões, sem tradução para o Brasil) admite que a coletividade suplanta a racionalidade do indivíduo e aponta que a teoria de Le Bon é desconfortável para leitores modernos, mas ela antecipou avanços teóricos observados no século XX. Para uma análise dessas propostas teóricas em maior detalhe, vide McGuire (1987).

Os avanços posteriores a 1950 são classificados por Jesus (2013) em torno de quatro grandes teorias modernas: a teoria da desindividuação, a teoria da identidade social, a teoria da convergência e o modelo da norma emergente.

A teoria da desindividuação sugere que os indivíduos se tornam mais desinibidos e impulsivos quando se mesclam à massa e formam assim um senso de anonimato (DIENER, 1980; REIMANN e ZIMBARDO, 2011). Reicher (2001), em contrapartida, discorda da explicação em torno do anonimato e sugere que o senso de empoderamento e a identificação com as normas do grupo explicam o comportamento do indivíduo quando em multidão.

O modelo da norma emergente (TURNER, apud JESUS, 2013) estabelece que as multidões se organizam em torno de cognições sociais em comum, preservando os traços individuais. As normas emergem das interações simbólicas entre os envolvidos, assim como também emergem os papéis de líderes e seguidores. Fehr e Fischbacher (2004) acrescentam que ainda se sabe pouco sobre como as normas são construídas, mas observam que as sanções praticadas espontaneamente entre membros do grupo podem conduzir os indivíduos a objetivos não egoístas e facilitar a cooperação.

A teoria da identidade social (TAJFEL e TURNER, 1979) pressupõe que as pessoas compartilham crenças e sentimentos com o grupo e se comprometem com a ação coletiva. A existência de exogrupos ${ }^{2}$ (como a polícia, em confronto com as multidões) e a formulação de discursos por membros representativos do endogrupo terminam por construir as noções de "nós" pela contraposição a "eles" (DRURY e REICHER, 1999). Assim se forma a solidariedade com o grupo, especialmente quando a identidade coletiva se torna mais proeminente do que a identidade pessoal (SIMON et al., 1998; TURNER, BROWN, TAJFEL, 1979).

A teoria da convergência pressupõe que as pessoas que desejam fazer parte de uma multidão decidem abandonar as cognições e comportamentos que destoam da maioria. Esse argumento encontra base na teoria da dissonância cognitiva de Festinger (1975). Segundo essa teoria, diante de duas crenças incompatíveis, mas de mesma importância, o indivíduo tende a escolher uma e rejeitar a outra. Depois de feita a escolha, busca razões que justifiquem a crença escolhida e razões que desqualifiquem a crença rejeitada. Logo, após escolher pertencer a um grupo, o indivíduo busca justificativas racionais para o abandono de suas concepções anteriores e para a adoção das ideias do grupo.

\footnotetext{
2 Entende-se por exogrupo a "unidade social com a qual o indivíduo não se identifica ou da qual não faz parte"; sendo endogrupo exatamente o oposto disto, i.e., "unidade social com a qual o indivíduo se identifica ou da qual faz parte" (James, 1986).
} 
Enquanto a teoria da desindividuação sustenta a tese leboniana da irracionalidade da multidão, as teorias da identidade social e da convergência admitem que o indivíduo escolhe participar da multidão e faz avaliações cognitivas sobre essa participação. A teoria da norma emergente escapa à discussão sobre racionalidade-irracionalidade e sugere um "caminho natural" resultante das interações simbólicas dos indivíduos (no plano cognitivo, ressalte-se; Le Bon e outros autores citados preocupam-se com aspectos afetivos e irracionais).

Além das teorias apontadas por Jesus (2013) acima, acrescenta-se aqui o estudo experimental em torno da noção de contágio de objetivos (AARTS, GOLLWITZER, HASSIN; 2004). Dik e Aarts (2007) argumentam que, quando um indivíduo A infere o esforço de B em direção a um objetivo, isso facilita a ocorrência do comportamento de A em direção ao mesmo (suposto) objetivo - a isso os autores chamam de contágio de objetivos. Os autores concluem que as atividades dirigidas a objetivos podem ser transmitidas de uma pessoa para outra, durante interações sociais corriqueiras, de maneira impensada.

Merece destaque, pelo viés positivo no estudo das influências entre membros de um mesmo grupo, o trabalho de Gomes e Maheirie (2011). As autoras investigaram, por meio de entrevistas, a influência exercida entre os participantes do Movimento Passe Livre em Florianópolis. Concluem as autoras que os participantes exercem uma influência mútua, constroem laços de amizade e combinam a militância com as atividades do dia a dia entre amigos. Além disso, parte dos entrevistados relatou ter em seus pais, professores e amigos os modelos de atividade política (corroborando MCCLURG, 2003; MCFARLAND e THOMAS, 2006). Os participantes do movimento sentem-se felizes por tomar parte em algo que vai além deles, "participando da vida de outras pessoas, transformando sujeitos e contextos, carregando significados, levando ao mundo sua criação e a si mesm[os]" (GOMES e MAHEIRIE, 2011; p. 370). Esse estudo aponta, portanto, para o efeito que a participação política coletivamente organizada tem sobre a constituição psicológica do indivíduo; destaca que o indivíduo dá significado consciente para aquilo que ele faz como membro do grupo (corroborado por MCCLURG, 2003).

\section{Evidências empíricas}

As evidências empíricas em favor do contágio comportamental aparecem em estudos esparsos. Geralmente com o uso de metodologia experimental, avalia-se o contágio comportamental relacionado a rir de uma piada (FREEDMAN e PERLICK, 1979), expressar emoções positivas ou negativas (BONO e ILIES, 2006) ou formular opiniões (KRASSA, 1988), envolver-se em atividades criminosas ou de risco (JONES e JONES, 1995), valendo registrar que a literatura não se limita a estes exemplos.

Evidências da implicação do contágio para a participação política foram identificadas por meio de questionários, por exemplo, por Djupe e Grant (2001), McClurg (2003), McFarland 
e Thomas (2006). A medida do contágio por meio de questionários está sujeita aos limites do método, uma vez que ao responder questionários o participante "filtrará" suas respostas com base naquilo que entende ser desejável pela sociedade em que vive (PASQUALI, 2010). Logo, seria ingênuo esperar que um participante respondesse de maneira isenta a itens que tentem aferir quão irracional foi sua decisão de participar de uma ação coletiva. Essa medida do grau de irracionalidade somente pode ser obtida em estudos experimentais (como o de DIK e AARTS, 2007), e a interpretação subjetiva sobre a participação em uma ação coletiva é mais bem captada em estudos qualitativos (como o de GOMES e MAHEIRIE, 2011). O uso de questionários, entretanto, continua produzindo resultados importantes, desde que não envolva questões que tratem da irracionalidade das ações coletivas. Os questionários podem ser utilizados para avaliar a correlação entre as características da rede social do participante (quantas pessoas agem da mesma maneira, qual a proximidade delas em relação ao participante) e os comportamentos que se busca avaliar (como a ação política, neste caso).

\section{Qual a contribuição dos estudos sobre contágio comportamental?}

Os variados conceitos, criados pelos teóricos citados neste artigo, apontam para o mesmo caminho: os indivíduos tendem a ajustar seus comportamentos conforme a multidão ou grupo ao seu redor, seja para ações políticas, seja em outras esferas da vida. Cada teoria propõe uma explicação diferente para os mesmos comportamentos, e essas explicações não são mutuamente excludentes. Pelo contrário: essas explicações revelam os variados olhares que podem ser lançados sobre um dado episódio de ação coletiva, espontânea ou organizada.

É possível considerar que o contágio - cuja natureza pode ser cognitiva, afetiva ou mesmo instintiva - seja um elemento importante para a compreensão da ação coletiva, especialmente para explicar os recentes episódios de multidões formadas com um notável grau de espontaneidade, muitas vezes sem uma liderança bem-definida. Não obstante, para além das manifestações populares em vias públicas, o contágio comportamental pode ser importante e necessário para compreender o que leva as pessoas a transformar suas intenções em ações, como envolver-se em trabalhos comunitários com implicações políticas (DJUPE e GRANT, 2001), doar dinheiro para um candidato ou votar nele (SHACHAR e NALEBUFF, 1999), candidatar-se a um cargo político (MATLAND, 2005; MATLAND e STUDLAR, 1996). De modo geral, o contágio comportamental parece aumentar as chances de um indivíduo se envolver em novas oportunidades de ação política (CHO e RUDOLPH, 2008; GOMES e MAHEIRIE, 2011; MCCLURG, 2003; MCFARLAND e THOMAS, 2006).

O contágio comportamental embaça a fronteira entre o comportamento individual e o coletivo (MCGUIRE, 1987). Isso reverbera os anseios de CHO e RUDOLPH (2008), que criticaram a tendência das ciências sociais de medir o comportamento individual e fazer inferências sobre a coletividade. O contágio comportamental pode ser minimamente necessário 
para a ação política organizada acontecer — afinal, as ações políticas ocorrem sobretudo com a mobilização de interesses coletivos, raramente por interesse de um indivíduo tomado isoladamente. Novas questões empíricas podem derivar do estudo do contágio. Parece ser bastante produtivo avaliar se, quando o indivíduo A observa o indivíduo B participar de uma ação política, as chances de participação de A na mesma ação aumentam ou não. Pode-se admitir, ainda, que a presença de uma quantidade maior de pessoas politicamente ativas próximas a A pode levá-lo a chances ainda maiores de participação. Aliás, se os achados empíricos certificarem que é mais comum agir coletivamente, caberá uma provocativa inversão: o que levaria um indivíduo a agir sozinho? Seria possível pensar a ação política de um indivíduo isolado? Diante dos acontecimentos políticos mais relevantes do Brasil desde a década de 1980, podemos desconfiar que, mais do que uma percepção individual, é preciso que haja um entendimento compartilhado posto em movimento em ações políticas.

\section{O contágio comportamental e os grandes momentos políticos do Brasil}

Tomando-se um recorte da década de 1980 aos dias atuais, três grandes momentos políticos marcados pela participação popular merecem destaque: o movimento Diretas Já (1983 e 1984), o Impeachment do Presidente Fernando Collor de Melo (1992) e as manifestações de junho de 2013.

O movimento Diretas Já se converteu em um marco relevante da participação política no Brasil. Teve peso importante para o encerramento de um período de 21 anos de ditadura militar, com dura repressão à liberdade de expressão e associação e com presidentes eleitos indiretamente por um Congresso Nacional em que a oposição se encontrava nitidamente enfraquecida (KINZO, 2001). Na ocasião, a opinião pública se descolou de noticiários hegemônicos do país, que assumiram um viés pró-regime e diminuíram a importância das manifestações (MIGUEL, 2001; PALHA, 2011). As manifestações cresceram, forçando uma mudança do discurso desses veículos de comunicação, que passaram a fazer uma divulgação em favor das eleições presidenciais diretas (BERTONCELO, 2009).

A campanha em favor das eleições diretas para presidente produziu uma memória de força política das massas como fator determinante para uma significativa mudança no regime de governo do país (BERTONCELO, 2009; MONTES e MEYER, 1984). Para BERTONCELO (2009), as Diretas Já representaram um rito de passagem, expressando a rejeição ao discurso de sustentação do regime de ditadura militar iniciado no Golpe Militar de 1964 e abrindo caminho para as pulsantes crenças democráticas. A noção de "rito de passagem" reverbera o argumento leboniano de que as revoluções expressam o abandono de velhas crenças em favor de novas, demarcando momentos de importante mudança e consolidação de uma nova visão de mundo. Há, portanto, um importante processo coletivo de transformação das ideias, de desconstrução de práticas instituídas e de demarcação, pela multidão, daquilo que "não se aceita mais" e daquilo 
que passa a se constituir um novo valor moral.

A percepção de capacidade de mudar o governo por meio de movimentos de massa seria reforçada em 1992, no episódio do Impeachment do Presidente Fernando Collor de Mello (BERTONCELO, 2009; BORGES FILHO, 2010; GOHN, 2009). Primeiro presidente eleito democraticamente após o regime militar, Fernando Collor de Mello assumiu o governo em um período em que o país enfrentava uma inflação desenfreada (de $84 \%$ ao mês, chegando a $2.000 \%$ ao ano).

Os três planos econômicos tentados durante o governo Collor envolveram medidas impopulares, como o confisco da poupança e o congelamento de salários. Os três planos fracassaram e as medidas adotadas desagradaram profundamente à população. E a situação do presidente não cessaria de piorar: escândalos de corrupção aniquilariam o que restava de sua popularidade (alcançando pífios 9\% de aprovação popular nas semanas anteriores ao Impeachment), e ele teria que enfrentar uma oposição crescente no Congresso Nacional (BETHELL e NICOLAU, 2008; SALLUM JÚNIOR e CASARÕES, 2011).

No dia da votação do Impeachment na Câmara dos Deputados, o gramado em frente ao Congresso Nacional encontrava-se tomado por uma multidão de "caras-pintadas": jovens (em grande parte, universitários) que pintaram o rosto com as cores da bandeira, com preto (simbolizando a desaprovação ao presidente) e palavras de ordem (BORGES FILHO, 2010; CÂMARA NOTÍCIAS, 2012; GOHN, 2009). Os "caras-pintadas" representaram um movimento estético em favor da ética na política, tendo marcado simbolicamente a memória popular (BORGES FILHO, 2010; BETHELL e NICOLAU, 2008), produzindo um novo "rito de passagem". Esse registro representaria o poder popular, especialmente a força de organização da juventude universitária para expressar a desaprovação em relação aos governantes (GOHN, 2009). Essa força somente voltaria a se mostrar, com novas bandeiras, após pouco mais de 20 anos.

No dia 6 de junho de 2013, estudantes universitários paulistas, em grande parte membros do Movimento Passe Livre (MPL), iniciam uma série de protestos contra o aumento das tarifas de ônibus na cidade de São Paulo, de R\$ 3,00 para R\$3,20 (ROMÃO, 2013). Enfrentaram dura repressão policial e uma cobertura midiática francamente contrária às manifestações (DAMASCENO, 2013; LIMA, 2013; NOGUEIRA, 2013; VION-DURY, 2013). Os manifestantes passaram a criticar abertamente os veículos de imprensa, a ponto de expulsar ou agredir jornalistas que faziam a cobertura de passeatas (FERNANDES, 2013; RAMOS, 2013; RANTHUM, 2013).

Variados outros confrontos entre manifestantes, polícia e imprensa ocorreram ao longo do mês (ANDRADE, AFFONSO, BIANCHI, 2013; FAVERO e DINIZ, 2013; PAES e ANTUNES, 2013). O debate migrou do acréscimo de $\mathrm{R} \$ 0,20$ nas tarifas de ônibus para o cerceamento da liberdade de expressão (MACEDO, 2013; ROMÃO, 2013), forçando o 
abrandamento da atuação policial e do discurso dos veículos jornalísticos (FERNANDES, 2013; RANTHUM, 2013; SECCO, 2013; SPIGARIOL, SHIMODA, FELIZATTE, BONICI, 2013).

Alguns episódios demarcaram essa mudança na cobertura jornalística (VION-DURY, 2013). Toma-se aqui um exemplo, dentre outros que são bastante discutidos nos textos citados no parágrafo anterior. O editorial da Folha de S. Paulo de 13 de junho defendeu o aumento do rigor policial para "Retomar a Paulista" (FOLHA DE S. PAULO, 2013). No dia seguinte, 14 de junho, o jornal publica a foto de uma de suas jornalistas, gravemente atingida por uma bala de borracha disparada pela polícia, além de mencionar outros 14 jornalistas feridos (RIGHETTI, 2013). A imagem da jornalista ferida, em contraponto ao editorial do dia anterior, correu as redes sociais via internet e somou-se a uma série de outras imagens e narrativas impactantes que denunciavam a "cobertura enviesada da grande mídia".

Gustave Le Bon (2008), em "Psicologia das Multidões", explica que as imagens têm um poder muito maior do que as estatísticas para impressionar e mobilizar uma multidão. Para o autor,

Não são os fatos em si que afetam a imaginação popular, mas o modo como se apresentam. Por condensação, se posso assim me exprimir, esses fatos devem produzir uma imagem impactante que preencha e atormente o espírito. (LE BON, 2008, p. 70).

As redes sociais de internet facilitaram o compartilhamento de relatos sobre as manifestações, contrapondo-se à descrição dos "grandes jornais" (DAMASCENO, 2013; FERNANDES, 2013; RANTHUM, 2013; LIMA, 2013). Essa rápida divulgação de imagens e relatos sobre as manifestações pode ter produzido um efeito catalisador da mobilização, persuadindo um número cada vez maior de pessoas a ir às ruas. Algumas imagens ganharam notório destaque:

(...) a imagem protagonizada em Brasília, no dia 17, quando centenas de pessoas ocuparam a área externa do Congresso Nacional, inclusive a famosa rampa e as bacias que compõem a edificação, parecem (sic) ter mostrado ao país que, de fato, algo novo estava acontecendo (RANTHUM, 2013).

Outras imagens e narrativas podem ser consideradas emblemáticas, como a mudança de discurso do jornalista Arnaldo Jabor, no Jornal Nacional (FERNANDES, 2013; SECCO, 2013), a expulsão do jornalista Caco Barcellos e sua equipe da cobertura de uma manifestação em Brasília (RANTHUM, 2013) e agressões a jornalistas de variados jornais identificados pelos manifestantes como "a grande mídia" (RANTHUM, 2013; SPIGARIOL, SHIMODA, FELIZATTE, BONICI, 2013; VION-DURY, 2013).

Em seu auge, no dia 20 de junho, segundo a Confederação Nacional dos Municípios (CNM), quase 2 milhões de pessoas foram às ruas em 438 cidades (LEAL, 2013). As manifestações eram convocadas em mídias sociais, e era notável o rechaço dos manifestantes à constituição de uma liderança organizada e à participação de partidos políticos (MOREIRA e 
SANTIAGO, 2013; NOGUEIRA, 2013). A convocação horizontal, distanciada das organizações tradicionais (partidos, sindicatos, etc.) é uma prática que vem se consolidando, particularmente entre os mais jovens (BRUSSINO, RABIA, SORRIBAS, 2008; EKMAN, AMNÅ, 2012; INGLEHART, CATTERBERG, 2002). Para Zibechi (2013), essa nova forma de organização deixou evidentes as limitações dos movimentos partidários e das organizações nascidas na década de 1980. Zibechi critica a alegada "espontaneidade" dos movimentos de junho, pois havia neles uma profunda conexão com movimentos populares iniciados anos antes, e que instalaram na população nova cultura política. Esse argumento se assemelha ao de Le Bon, quando este afirma que as multidões tomam consciência de sua força, como resultado da "propagação de certas ideias lentamente implantadas nos espíritos" (p.21).

Ao longo do mês, a pauta de reivindicações ganhou novos itens, como o fim voto secreto nas decisões parlamentares,; a rejeição da PEC 37/2011³, a apreciação dos projetos de reforma política (mudanças nas regras eleitorais), melhorias no transporte público, maiores investimentos em educação e saúde públicas, maior transparência nos gastos públicos (especialmente aqueles relacionados à Copa do Mundo de 2014), punição para políticos envolvidos em desvios de dinheiro público e repúdio à violência policial, entre outros (ABREU e MEDEIROS, 2013; RANTHUM, 2013; ROMÃO, 2013). Nogueira (2013) explica que as razões para a efervescência das massas eram palpáveis. O alvo das manifestações parecia ser difuso, mas a raiz do incômodo era evidente:

$\mathrm{O}$ que se questionou, portanto, foi o arranjo político protagonizado por pessoas, grupos e classes, interesses econômicos e organizações que, por vias ora dissimuladas ora explícitas, têm-se associado para governar o país. A crise que temos diante dos olhos é mais que crise política: é crise de um sistema perverso, que encontra apoio em múltiplos aspectos, econômicos, socioculturais, políticos, éticos, institucionais, governamentais (NOGUEIRA, 2013, p. 20).

A resposta dos órgãos governamentais não apresentou articulação no mesmo ritmo que o crescimento da série de manifestações (ANTUNES, 2013; CHAGAS, 2013; MORAES, 2013; NOGUEIRA, 2013; RANTHUM, 2013). Houve, não obstante, o anúncio de uma série de medidas. Com respeito às passagens de ônibus, em São Paulo, Rio de Janeiro e em mais 15 cidades as autoridades anunciaram o cancelamento de reajustes, a diminuição de seu percentual ou mesmo a redução efetiva da tarifa. A Presidente da República fez um pronunciamento em que anunciou um pacto com cinco itens, em atenção às reivindicações dos populares. $\mathrm{O}$ Congresso Nacional votou às pressas um projeto que torna a corrupção um crime hediondo. A

\footnotetext{
${ }^{3}$ Apelidada de "PEC da Impunidade", propunha que a atividade de investigação fosse competência exclusiva das Polícias Civis dos Estados e Distrito Federal, e da Polícia Federal. Isto retiraria o poder de investigação de outras instituições, especialmente do Ministério Público, que vinha sendo apontado como uma instituição com expressiva atuação no combate à corrupção (Ribeiro, 2013). A PEC 37/2011 foi rejeitada em 25 de junho de 2013 - tendo contribuído para o resultado da votação o clamor das ruas, nas manifestações de junho de 2013 (Jornal da Câmara, 2013).
} 
Polícia Federal prendeu, por ordem do Supremo Tribunal Federal, o deputado Natan Donadon (PMDB-RO), o primeiro a ser encarcerado por determinação do STF desde a Constituição de 1988 (para mais detalhes sobre as medidas anunciadas nesse período, vide RANTHUM, 2013).

\section{Conclusões}

As manifestações brasileiras parecem desenhar uma gradação quanto ao objetivo democrático a ser alcançado. As Diretas Já visavam à instituição de regras democráticas para escolha do chefe de Estado (BERTONCELLO, 2009; CAMARGO, HIPPOLITO, D'ARAÚJO, FLASKMAN, 1986; MONTES e MEYER, 1984); os caras-pintadas derrubaram um presidente eleito, em rechaço à corrupção e a medidas econômicas ineficazes (BORGES FILHO, 2010; SALLUM JÚNIOR e CASARÕES, 2011). Entre as Diretas Já! e o Impeachment de Collor, houve uma substancial ampliação da participação política e da contestação pública (BETHELL e NICOLAU, 2008; KINZO, 2001).

As manifestações de junho de 2013 exigiam uma atuação ética dos governantes e a adequada aplicação dos recursos públicos, além de levar a novo patamar a luta por liberdade de expressão, provocando mudanças no discurso da imprensa e na repressão policial (NOGUEIRA, 2013; RANTHUM, 2013; ROMÃO, 2013; SPIGARIOL, SHIMODA, FELIZATTE, BONICI, 2013; VION-DURY, 2013). Essas manifestações podem ser certamente encaradas como um episódio relevante para a cultura política brasileira.

Em comum, os três episódios analisados (Diretas Já, Impeachment de Collor e manifestações de junho de 2013) têm em comum a espontaneidade, uma vez que nasceram de movimentos pequenos e se multiplicaram rapidamente por várias cidades (BETHELL e NICOLAU, 2008; NOGUEIRA, 2013). Isso reverbera os argumentos de Le Bon (2008) de que as multidões não precisam estar em um mesmo lugar, mas sim devem estar movidas pelos mesmos sentimentos diante dos acontecimentos nacionais. Além disso, os três episódios demarcaram a rejeição de velhas crenças em favor de novas (BERTONCELO, 2009; KINZO, 2001; RANTHUM, 2013; ROMÃO, 2013).

Neste artigo, as manifestações foram analisadas sob uma perspectiva estritamente teórica, uma vez que não se coletaram dados naqueles contextos. Não obstante, o contágio comportamental parece oferecer uma parcela importante da explicação sobre a formação dos movimentos de massa. Ao agir coletivamente, a intenção (motivações ou atitudes, no jargão da psicologia) pode ter maior propensão a se converter em ação do que nas situações em que um indivíduo tenta agir sozinho. Isso parece uma questão empírica relevante para questionários, experimentos e entrevistas em estudos futuros. 


\section{Referências}

AARTS, Henk; GOLLWITZER, Peter M.; HASSIN, Ran R. Goal contagion: perceiving is for pursuing. Journal of personality and social psychology, v. 87, n. 1, p. 23-27, 2004.

ABERTURA do processo de impeachment de Collor completa 20 anos. Câmara Notícias. 28 set. 2012. Disponível em: <http://www2.camara.leg.br/camaranoticias/noticias/ POLITICA/427000-ABERTURA-DO-PROCESSO-DE-IMPEACHMENT-DE-COLLORCOMPLETA-20-ANOS.html>. Acesso em 10 out. 2013.

ABREU, Diego; MEDEIROS, Étore. Da redução da passagem ao fim do voto secreto: são muitas as reivindicações. Correio Braziliense, 21 jun. 2013. Disponível em <http://www.correiobraziliense.com.br/app/ noticia/politica/2013/06/21/interna_politica, 372639/da-reducao-da-passagem-ao-fim-do-voto-secreto-sao-muitas-as-reivindicacoes.shtml>. Acesso em 10 out. 2013.

ANDRADE, Hanrrikson; AFFONSO, Julia; BIANCHI, Paula. Manifestantes entram em confronto com policiais no Rio e pelo menos 62 ficam feridos. UOL Notícias, 20 jun. 2013. Disponível em: <http://noticias.uol.com.br/cotidiano/ultimas-noticias/2013/06/20/em-frente-aprefeitura-do-rio-manifestantes-entram-em-confronto-com-policiais.htm>. Acesso em 10 out. 2013.

ANTUNES, Ricardo. As rebeliões de junho de 2013. Observatorio Social de América Latina, n. 34, p. 37-49, 2013.

BERTONCELO, Edison Ricardo Emiliano. "Eu quero votar para presidente": uma análise sobre a campanha das diretas. Lua Nova, v. 76, n. 76, p. 169-196, 2009.

BETHELL, Leslie; NICOLAU, Jairo. Politics in Brazil, 1985-2002. In: BETHELL, Leslie (Ed.). Brazil since 1930. Cambridge: Cambridge University Press, 2008. p. 231-282 (The Cambridge History of Latin America, 9).

BONO, Joyce E.; ILIES, Remus. Charisma, positive emotions and mood contagion. The Leadership Quarterly, v. 17, n. 4, p. 317-334, 2006.

BORGES FILHO, Nilson. Ética e Política. Seqüência: Estudos Jurídicos e Políticos, v. 14, n. 26, p. 28-32, 2010.

BRUSSINO, Silvina; RABBIA, Hugo; SORRIBAS, Patricia. Una Propuesta de Categorización de la Participación Política de Jóvenes Cordobeses. Psicologia Política, v. 8 n. 16, 285-304, 2008.

CACIOPPO, John T.; HAWKLEY, Louise C. Perceived social isolation and cognition. Trends in cognitive sciences, v. 13, n. 10, p. 447-454, 2009.

CAMARGO, Aspásia; HIPPOLITO, Lucia; D'ARAUJO, Maria Celina; FLASKMAN, Dora Rocha. Artes da Política: Diálogo Com Amaral Peixoto. Rio de Janeiro: Nova Fronteira, 1986. Disponível em: 〈http://bibliotecadigital.fgv.br/dspace/handle/10438/6756>. Acesso em: 15 jan. 2014.

CHAGAS, Paulo Victor. Cinco pactos foram a resposta do governo federal aos protestos de junho. Agência Brasil, $31 \mathrm{dez}$. 2013. Disponível em:

<http://memoria.ebc.com.br/agenciabrasil/noticia/2013-12-31/cinco-pactos-foram-resposta-dogoverno-federal-aos-protestos-de-junho>. Acesso em 10 out. 2013.

CHO, Wendy K. Tam; RUDOLPH, Thomas J. Emanating political participation: untangling the 
spatial structure behind participation. British Journal of Political Science, v. 38, n. 2, p. 273, 2008.

CIALDINI, Robert B.; TROST, Melanie R. Social influence: Social norms, conformity and compliance. In: GILBERT, D. T.; FISKE, S. T.; and LINDZEY, G. (Eds.), The handbook of social psychology. 4th ed. Boston: McGraw-Hill, 1998. v. 2, p. 151-192.

CONSOLIM, Maria Cristina. Posfácio. In: LE BON, Gustave. Psicologia das multidões. Tradução: Mariana Sérvulo da Cunha. São Paulo: Martins Fontes, 2008 (Obra original publicada em 1895).

DAMASCENO, Marcio. (2013, 14 de junho). Imprensa estrangeira destaca truculência da polícia brasileira em protestos. Deutsche Welle, 14 jun. 2013. Disponível em: <http://www.dw.de/imprensa-estrangeira-destaca-truculência-da-polícia-brasileira-emprotestos/a-16883228>. Acesso em 10 out 2013.

DIENER, Edward. Deindividuation: The absence of self-awareness and self-regulation in group members. In Paulus, P. B. (Org.), The psychology of group influence, Hillsdale: Erlbaum, 1980. p. 209-242.

DIK, Giel; AARTS, Henk. Behavioral cues to others' motivation and goal pursuits: The perception of effort facilitates goal inference and contagion. Journal of Experimental Social Psychology, v. 43, n. 5, p. 727-737, 2007.

DJUPE, Paul A.; GRANT, J. Tobin. Religious institutions and political participation in America. Journal for the Scientific Study of Religion, v. 40, n. 2, p. 303-314, 2001.

DRURY, John; REICHER, Steve. The intergroup dynamics of collective empowerment: Substantiating the social identity model of crowd behavior. Group Processes \& Intergroup Relations, v. 2, n. 4, p. 381-402, 1999.

EDITORIAL: Retomar a Paulista. Folha de S. Paulo, 13 jun. 2013. Disponível em: <http://www1.folha.uol.com.br/opiniao/2013/06/1294185-editorial-retomar-a-paulista.shtml>. Acesso em 09 out. 2013.

EKMAN, Joakim; AMNÅ, Erik. Political participation and civic engagement: Towards a new typology. Human Affairs, v. 22, n. 3, p. 283-300, 2012.

FAVERO, Daniel; DINIZ, Fernando. RS: protesto em Porto Alegre acaba em saques e confrontos; 20 são presos. Terra Notícias, 20 jun. 2013. Disponível em:

$<$ http://noticias.terra.com.br/brasil/cidades/rs-protesto-em-porto-alegre-acaba-em-saques-econfrontos-20-sao-presos,d88095c85046f310VgnVCM1 0000098cceb0aRCRD.html>. Acesso em 11 out. 2013.

FEHR, Ernst; FISCHBACHER, Urs. Social norms and human cooperation. Trends in cognitive sciences, v. 8, n. 4, p. 185-190, 2004.

FERNANDES, Paula. Manifestações - o que você não viu na TV. O Casarão, 9 jul. 2013. Disponível em: <http://jornalocasarao.com/2013/07/09/manifestacoes-o-que-voce-nao-viu-natv/>. Acesso em: 11 out. 2013.

FESTINGER, Leon. Teoria da dissonância cognitiva. Zahar, 1975.

FREEDMAN, Jonathan L.; PERLICK, Deborah. Crowding, contagion, and laughter. Journal of Experimental Social Psychology, v. 15, n. 3, p. 295-303, 1979. 
FREUD, Sigmund. Psicologia das massas e a análise do Eu. In: Obras Completas de Sigmund Freud. Tradução: Paulo César de Sousa. São Paulo: Companhia das Letras, 1921. v.15.

GOHN, Maria da Glória Marcondes. Lutas e movimentos pela educação no Brasil a partir de 1970. Eccos Revista Científica, v. 11, n. 1, p. 23-38, 2009.

GOMES, Marcela de Andrade; MAHEIRIE, Kátia. Passe Livre Já: participação política e constituição do sujeito. Revista Psicologia Política, v. 11, n. 22, p. 359-375, 2011.

INGLEHART, Ronald; CATTERBERG, Gabriela. Trends in political action: The developmental trend and the post-honeymoon decline. International Journal of Comparative Sociology, v. 43, n.3-5, p. 300-316, 2002.

JESUS, Jaqueline Gomes de. Psicologia das massas: contexto e desafios brasileiros. Psicologia \& Sociedade, v. 25, n. 3, p. 493-503, 2013.

JONES, Marshall B.; JONES, D. R. Preferred pathways of behavioral contagion. Journal of psychiatric research, v. 29, n. 3, p. 193-209, 1995.

CÂMARA rejeita PEC 37; texto será arquivado. Jornal da Câmara, 26 jun. 2013. p.3

KONDER, Leandro. O que é dialética. São Paulo: Brasiliense, 1984.

KINZO, Maria D'Alva G. A democratização brasileira: um balanço do processo político desde a transição. São Paulo em perspectiva, v. 15, n. 4, p. 3-12, 2001.

KRASSA, Michael A. Social groups, selective perception, and behavioral contagion in public opinion. Social Networks, v. 10, n. 2, p. 109-136, 1988.

LE BON, Gustave. Psicologia das multidões. Tradução: Mariana Sérvulo da Cunha. São Paulo: Martins Fontes, 2008 (Obra original publicada em 1895).

LEAL, Aline. (2013, 21 de junho). Quase 2 milhões de brasileiros participaram de manifestações em 438 cidades. Agência Brasil. 21 jun. 2013. Disponível em: $<$ http://memoria.ebc.com.br/agenciabrasil/noticia/2013-06-21/quase-2-milhoes-de-brasileirosparticiparam-de-manifestacoes-em-438-cidades >. Acesso em 13 out. 2013.

LIMA, Venício A. As manifestações de junho e a mídia. Observatório de Imprensa, 25 jun. 2013. Disponível em: <http://www.observatoriodaimprensa.com.br/news/view/ _ed752_as_manifestacoes_de_junho_e_a_midia >. Acesso em 09 out. 2013.

MACEDO, Fausto. O povo tem o direito de ir à rua, diz chefe do MP de SP. Estadão.com.br, 25 jun. 2013. Disponível em: <http://www.estadao.com.br/noticias/ nacional,o-povo-tem-odireito-de-ir-a-rua-diz-chefe-do-mp-de-sp,1046705,0.htm>. Acesso em: 09 out. 2013.

MATLAND, Richard E. Enhancing women's political participation: legislative recruitment and electoral systems. In: J. BALLINGTON, J.; KARAM, A. (Eds.). Women in parliament: Beyond numbers. Stockholm: International Institute for Democracy and Electoral Assistance (IDEA), 2005. p. 93-111.

MATLAND, Richard E.; STUDLAR, Donley T. The contagion of women candidates in singlemember district and proportional representation electoral systems: Canada and Norway. The journal of politics, v. 58, n. 03, p. 707-733, 1996.

MCCLURG, Scott D. Social networks and political participation: The role of social interaction 
in explaining political participation. Political Research Quarterly, v. 56, n. 4, p. 449-464, 2003.

MCDOUGALL, William. (1927). The group mind. Cambridge: Cambridge University Press. Disponível em: <https://archive.org/details/groupmind032676mbp>. Acesso em: 16 jan. 2014.

MCFARLAND, Daniel A.; THOMAS, Reuben J. Bowling young: How youth voluntary associations influence adult political participation. American sociological review, v. 71, n. 3, p. 401-425, 2006.

MCGUIRE, Gregory R. Pathological subconscious and irrational determinism in the social psychology of the crowd: the legacy of Gustave LeBon. Advances in psychology, v. 40, p. 201$217,1987$.

MIGUEL, Luis Felipe. Meios de comunicação de massa e política no Brasil. Diálogos latinoamericanos, v. 3, p. 43-70, 2001.

MIGUEL, Luis Felipe. A Democracia Domesticada: Bases Antidemocráticas do Pensamento Democrático Contemporâneo. Dados, v. 45, n. 3, p. 483-511, 2002.

MONTES, Maria Lúcia; MEYER, Marlyse. Festa na política. Lua Nova: Revista de Cultura e Política, v. 1, n. 3, p. 85-89, 1984.

MORAES, Geórgia. Manifestações de junho e a resposta do Poder Público: 1 milhão de brasileiros surpreendem as autoridades - Bloco 1. Câmara Notícias, 11 jul. 2013. Disponível em: <http://www2.camara.leg.br/camaranoticias/radio/materias/ REPORTAGEMESPECIAL/446979-MANIFESTACOES-DE-JUNHO-E-A-RESPOSTA-DO-PODERPUBLICO-1-MILHAO-DE-BRASILEIROS-SURPREENDEM-AS-AUTORIDADESBLOCO-1.html>. Acesso em: 09 out. 2013.

MOREIRA, Orlandil de Lima; SANTIAGO, Idalina Maria Freitas Lima. Vem prá rua: os protestos de junho. In: Sousa, C. M.; Souza, A. A. (Orgs.). Jornadas de junho: repercussões e leituras, Campina Grande-PB: Eduepb, 2013. p. 13-21.

MOSCOVICI, Serge. L'âge des foules: un traité historique de psychologie des masses. Bruxelles: Les Éditions Complexe, 1985. Disponível em: <http://classiques.uqac.ca/ contemporains/moscovici_serge/age_des_foules/age_des_foules.pdf $>$. Acesso em: 16 jan. 2014.

NICOL, C. J. The social transmission of information and behaviour. Applied Animal Behaviour Science, v. 44, n. 2, p. 79-98, 1995.

NYE, Robert A. Two paths to a psychology of social action: Gustave Lebon and Georges Sorel. The Journal of Modern History, p. 411-438, 1973.

NOGUEIRA, Marco Aurélio. As ruas e a democracia: ensaios sobre o Brasil contemporâneo. Rio de Janeiro: Contraponto, 2013.

PAES, Cíntia; ANTUNES, Sara. (2013, 23 de junho). Confronto entre policiais e ativistas marca protesto com 70 mil em BH. G1, 23 jun. 2013. Disponível em:

$<$ http://g1.globo.com/minas-gerais/noticia/2013/06/confronto-entre-policiais-e-ativistas-marcaprotesto-com-70-mil-em-bh.html>. Acesso em 09 out. 2013.

PALHA, Cássia Rita Louro. Televisão e política: o mito Tancredo Neves entre a morte, o legado e a redenção. Revista Brasileira de História, v. 31, n. 62, p. 217-234, 2011.

RAMOS, Natalia. A imprensa, outro alvo dos manifestantes no Brasil. AFP, 20 jun. 2013. 
Disponível em: <http://br.noticias.yahoo.com/imprensa-outro-alvo-dos-manifestantes-brasil205948389.html>. Acesso em: 09 out. 2013.

RANTHUM, Rodrigo. Um ensaio sobre o mês de junho de 2013. Observatório da Imprensa, 16 jul. 2013. Disponível em: <http://www.observatoriodaimprensa.com.br/ news/view/_ed755_um_ensaio_sobre_o_mes_de_junho_de_2013>. Acesso em: 09 out. 2013.

REICHER, Stephen. The psychology of crowd dynamics. In: Hogg, M. A.; Tindale, R. S. (Orgs.). Blackwell handbook of social psychology: Group processes, Oxford: Blackwell, 2001. p. 182-208.

REIMANN, Martin; ZIMBARDO, Philip G. The dark side of social encounters: Prospects for a neuroscience of human evil. Journal of Neuroscience, Psychology, and Economics, v. 4, n. 3, p. 174, 2011.

RIBEIRO, Marcelle. Integrantes do MP realizam atos contra a 'PEC da Impunidade'. O Globo, 12 abr. 2013. Disponível em: <http://oglobo.globo.com/pais/integrantes-do-mp-realizam-atoscontra-pec-da-impunidade-8100026>. Acesso em 10 out. 2013.

RIBEIRO, Maria Thereza Rosa. Antes Tarde do que nunca. Gabriel Tarde e a emergência das ciências sociais. Revista de Antropologia, v. 44, n. 1, p. 325-330, 2001.

RIGHETTI, Sabine. Pelo menos 15 jornalistas ficaram feridos durante cobertura de protesto em SP. Folha de S. Paulo, 14 jun. 2013. Disponível em:

<http://www1.folha.uol.com.br/cotidiano/2013/06/1295433-pelo-menos-15-jornalistas-ficaramferidos-durante-cobertura-de-protesto-em-sp.shtml>. Acesso em 09 out. 2013.

ROMÃO, Wagner de Melo. As Manifestações de Junho e os desafios à Participação institucional. In: INSTITUTO DE PESQUISA ECONÔMICA APLICADA (IPEA), Boletim de Análise Político-Institucional. Rio de Janeiro: IPEA, 2013. p. 11-17.

RYLE, Gilbert. The concept of mind. London: Hutchinson House, 1951 (Obra original publicada em 1949).

SALLUM JÚNIOR, Brasilio; CASARÕES, Guilherme Stolle Paixão. O impeachment do presidente Collor: a literatura e o processo. Lua Nova: Revista de Cultura e Política, n. 82, p. 163-200, 2011.

SANDOVAL, Salvador. A. (1997). O comportamento político como campo interdisciplinar de conhecimento: a reaproximação da sociologia e da psicologia social. In: CAMINO, L.; LHULHIER, L.; SANDOVAL, S. (Orgs.). Estudos sobre comportamento político. Florianópolis: Letras Contemporâneas, 1997. p. 13-24.

SECCO, Lincoln. Manifestantes serão enjaulados no discurso da Grande Imprensa? Viomundo, 8 jun. 2013. Disponível em: <http://www.viomundo.com.br/politica/ lincoln-secco-viradapolitica.html>. Acesso em: 08 out. 2013.

SHACHAR, Ron; NALEBUFF, Barry. Follow the leader: Theory and evidence on political participation. American Economic Review, p. 525-547, 1999.

SIMON, Bernd; LOEWY, Michael; STÜRMER, Stefan; WEBER, Ulrike; FREYTAG, Peter; HABIG, Corinna; KAMPMEIER, Claudia; \& SPAHLINGER, Peter. Collective identification and social movement participation. Journal of personality and social psychology, v. 74, n. 3, p. 646-658, 1998.

SMELSER, Neil. J. Theory of collective behavior. New York: The Free Press, 1965. 
Disponível em: <https://archive.org/details/theoryofcollecti00smel>. Acesso em: 14 jan. 2014.

SPIGARIOL, André; SHIMODA, Carolina; FELIZATTE, Rafael; BONICI, Stella. Especial protestos pelo Brasil: por trás da notícia. JPress, 21 jun. 2013. Disponível em: < http://jpress.jornalismojunior.com.br/2013/06/especial-protestos-brasil/ >. Acesso em 1 out. 2013.

TAJFEL, Henri; TURNER, John C. An integrative theory of intergroup conflict. In WORCHEL, S.; AUSTIN W. G. (Orgs.). The social psychology of intergroup relations. Chicago: Nelson-Hall, 1979. p.33-47.

TROTTER, Wilfred. Instincts of the Herd in Peace and War. London: Adelphi Terrace, 1921. Disponível em: <https://archive.org/details/instinctsofherdi00trot>. Acesso em: 15 jan. 2014.

TURNER, John C.; BROWN, Rupert J.; TAJFEL, Henri. Social comparison and group interest in ingroup favouritism. European Journal of Social Psychology, v. 9, n. 2, p. 187-204, 1979.

VAN STEKELENBURG, Jacquelien; KLANDERMANS, Bert. The social psychology of protest. Current Sociology, v. 61, n. 5-6, p. 886-905, 2013.

VION-DURY, Philippe. Corruption, mauvaise gestion: São Paulo s'enflamme. Le nouvel Observateur, 14 jun. 2013. Disponível em: <http://rue89.nouvelobs.com/2013/06/14/face-acorruption-mauvaise-gestion-les-rues-sao-paulo-senflamment-243313 >. Acesso em : 11 out. 2013.

ZIBECHI, Raúl. Debajo y detrás de las grandes movilizaciones. Observatorio Social de América Latina, n. 34, p. 15-35, 2013.

ZIMMERMANN, Eduardo A. Racial ideas and social reform: Argentina, 1890-1916. Hispanic American Historical Review, v. 72, n. 1, p. 23-46, 1992.

Artigo recebido em: 06/06/2014

Artigo aceito para publicação em: 06/08/2014 